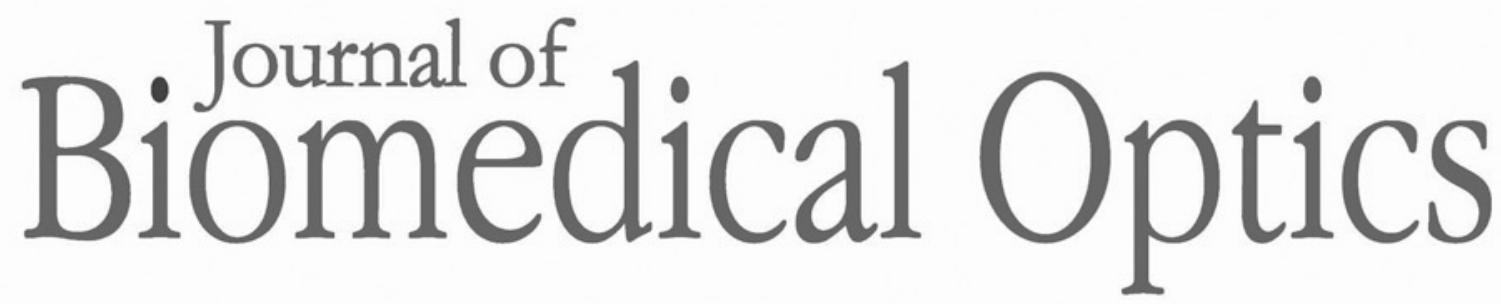

BiomedicalOptics.SPIEDigitalLibrary.org

\title{
Shining Future of Biomedical Optics
}

\author{
Lihong V. Wang
}




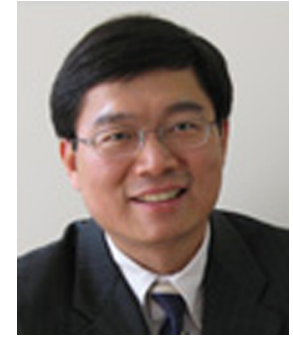

\section{Shining Future of Biomedical Optics}

Time flies. At the end of 2017 , I will have served as the editorin-chief of the Journal of Biomedical Optics (JBO) for eight years. I feel it is the right time for me to step down as editor for multiple reasons. First and foremost, we need new insights to improve JBO from a different perspective; eight (1000 in binary) years, give or take, seems to be a healthy cycle for such regeneration. Second, my lab's recent relocation to Caltech requires me to shift some energy to its renewal. Third, as my family is waiting for my daughter to graduate from high school, I am still commuting between St. Louis, Missouri, and Pasadena, California.

I am pleased that Brian Pogue of Dartmouth College, selected by the SPIE Board of Directors to assume the JBO editorship, has graciously agreed to serve in this role, effective January 2018. Brian has demonstrated tremendous leadership in our field. His laboratory has played key roles in the development of diffuse optical tomography and Cherenkov radiation imaging. He has served as a member of the JBO editorial board since 2007. I have no doubt that Brian will lead JBO to an even greater level to serve our community better.

I am grateful to SPIE for entrusting me with this important position. It has been such a pleasure to work with the journal staff. In particular, I want to thank Karolyn Labes, journals manager; Gwen Weerts, managing editor; Rita Davis, peer review coordinator; and Eric Pepper, director of publications. Their prompt and thoughtful responses have greatly expedited the operation of the journal.

My predecessor, Bruce Tromberg, left huge shoes to fill. Under Bruce's stewardship, JBO grew from a fledgling young journal to a highly respected flagship in the field of biomedical optics. Bruce's wisdom has always been an important resource to JBO.

I must say that it has been a privilege to work with JBO's first-rate editorial board members. I truly appreciate their dedication and hard work, which have made JBO highly competitive in both peer-review quality and speed. In particular, Ricky Wang, the first letters editor, and Changhuei Yang, a topical editor and my Caltech colleague, deserve special mention. Ricky single-handedly managed all the letters in the first

(C) 2017 Society of Photo-Optical Instrumentation Engineers (SPIE) several years and shortened the review cycle dramatically. Changhuei has devoted countless hours to read each and every manuscript assigned to him, advancing our review quality to a new standard.

Last but not least, I thank all the special section guest editors, ad hoc guest editors, authors, and reviewers. Your contributions have made JBO possible.

It has been incredibly gratifying to see that JBO has significantly improved upon several metrics from 2009 to 2016. The total number of published papers per year increased from 322 to 419 , while the total number of submissions grew from 532 to 820 . The acceptance rate has been reduced from $68 \%$ to $43 \%$ due to our intentional tightening of acceptance criteria. Owing to the extreme diligence of the editorial board, we have proudly shortened the regular submission review cycle from 8.0 weeks to 5.3 weeks and the letter submission review cycle from 7.3 weeks to 3.7 weeks. Our JBO staff has also minimized every possible time lag, improving the average acceptance-to-publication times from 9.4 weeks to 3.6 weeks for regular papers and from 8.6 weeks to 3.3 weeks for letters. These review and publication speeds are highly competitive.

Starting in January 2011, JBO has been published monthly rather than bimonthly. We recognized that the bimonthly printed issues were unwieldy as well as untimely. Although papers are posted online as soon as they are copyedited, typeset, and approved, monthly publication has provided more manageable and timely print issues. Despite the cost, JBO decided to continue to support printing in the interest of some of our readers who prefer to read hard copies.

Since January 2013, JBO has added a new benefit for authors who support the journal through payment of optional page charges. Research articles for which such page charges are paid gain open access immediately on publication. All review and tutorial articles continue to enjoy unconditional open access, subsidized by SPIE. In addition, authors retain copyright for open access articles through a Creative Commons attribution license (CC-BY "gold open access"; see http://creativecommons.org/licenses/by/4.0/). This is the type of license that many employers and research-funding agencies prefer or require. Unlike most online-only journals, all accepted JBO articles are professionally copyedited and typeset and are promptly published online in the SPIE Digital Library.

We have published four highly selective "Pioneers in Biomedical Optics" special sections. We recognized Tayyaba Hasan in 2010 and Michael Feld posthumously in 2011 for their pioneering contributions in photochemistry and laser spectroscopy, respectively. We also honored two scientific giants in our field, Roger Tsien and Osamu Shimomura, in 2013 and 2015, respectively. They shared the 2008 Nobel Prize in Chemistry along with Martin Chalfie for the discovery and development of the green fluorescent protein.

Personally, I feel fortunate to work in the field of biomedical optics. To celebrate the contribution of optics to humankind, UNESCO proclaimed 2015 as the International Year of Light and Light-based Technologies. Light is truly special. The minute optical region of the vast electromagnetic spectrum is the only one that provides molecular information directly. Due to the fundamental importance of molecules 
to organisms, light plays a unique role in biology and medicine. Interfacing between engineering and biomedicine, biomedical optics will continue to shine in years to come and will find even greater impact in human health. I know that JBO will continue to support these endeavors through dissemination of the important new knowledge that continues to flow from the labs of those of us who work in this exceedingly exciting field.

\section{Lihong V. Wang \\ Editor-in-Chief}

